\title{
Pseudodiaptomus marinus Sato, 1913, a new invasive copepod in Lake Faro (Sicily): observations on the swimming behaviour and the sex-dependent responses to food
}

\author{
Luciana Sabia ${ }^{1,2,4^{*}}$, Marco Uttieri ${ }^{2}$, François G Schmitt ${ }^{3}$, Giacomo Zagami ${ }^{1}$, Enrico Zambianchi ${ }^{2}$ and Sami Souissi ${ }^{3}$
}

\begin{abstract}
Background: The calanoid copepod Pseudodiaptomus marinus Sato, 1913 is an estuarine-coastal species, living in shallow eutrophic inshore waters. It is native of the Indo-Pacific region, but in the last 50 years, it has successfully colonized new areas worldwide. P. marinus, first recorded in Lake Faro (Messina, Italy) in October 2008, is now a stable component of the zooplankton assemblage of the lake. By means of video recordings, for the first time, the swimming behaviour of males and non-ovigerous and ovigerous females of $P$. marinus has been studied. The individuals were filmed in the presence and absence of food to evaluate how the presence of prey might affect the swimming behaviour.

Results: The swimming motion showed marked sex-dependent features and responses to the presence of food. Mechanisms through which behaviour might influence the outcome of a new colonization were analysed. The behaviour of $P$. marinus was then compared with that of the congeneric Pseudodiaptomus annandalei showing the typical behaviour displayed by the representatives of the genus Pseudodiaptomus of living in proximity of the bottom.

Conclusions: Environmental and hydrological conditions in Lake Faro have likely provided the newly introduced $P$. marinus a suitable environment for settling, although normally the presence of an anoxic deep layer would be detrimental for a demersal species. In this case, the plasticity in the behaviour of P. marinus enhanced its capacity for colonising new environments. Switching from demersal to pelagic habitat or being fully planktonic allowed it to express its large individual variability in motion strategies and thus to successfully colonize the lake.
\end{abstract}

Keywords: Pseudodiaptomus marinus; Swimming behaviour; Invasive species; Sex-dependent behaviour

\section{Background}

Despite the great number of studies on the modifications induced by non-indigenous species (e.g., Galil 2009) in invaded ecosystems, studies on the effects of invasive zooplankton are still scarce (e.g., Choi et al. 2005; Cordell et al. 2008). Nevertheless, there is a continuously growing number of alien species in coastal ecosystems, particularly in temperate areas, both due to environmental changes

\footnotetext{
* Correspondence: luciana.sabia@uniparthenope.it

'Department of Biological and Environmental Sciences, University of Messina, V.le F. Stagno d'Alcontres,31, S. Agata-Messina 98166, Italy

'Department of Science and Technologies, University of Naples 'Parthenope',

Centro Direzionale di Napoli, Isola C4, Napoli 80143, Italy

Full list of author information is available at the end of the article
}

(Galil 2009) and to human activities, such as ballast water discharge and aquaculture (Galil 2009).

The Mediterranean is a site of intense invasions particularly by thermophilic species originating from the Indo-Pacific region (Galil 2009; Zenetos et al. 2010). The calanoid Pseudodiaptomus marinus is one of them, having entered the Mediterranean Sea in the last few years (De Olazabal and Tirelli 2011; Delpy et al. 2012; Zenetos et al. 2012). It is a typical estuarine-coastal copepod, living only in shallow inshore waters, often highly eutrophicated and is reported as herbivorous and detritivorous (Uye and Kasahara 1983). This species is known to live near the bottom during the day (Valbonesi and Harada 1980; Fleminger and Hendrix Kramer 1988; Liang and Uye 1997), feeding 
on detritus through the creation of feeding currents (Uye and Kasahara 1983), while at night, it moves along the water column likely exploiting different food sources (Uye and Kasahara 1983; Valbonesi and Harada 1980). The feeding behaviour is similar for both adult sexes but different from the copepodite and nauplii stages (Uye and Kasahara 1983).

P. marinus was first described by Sato (1913) from embayment along the west coast of Japan, where it was found as a perennial species (Hirota 1962; Uye et al. 1982). It was studied for a long time in the Sea of Japan (Liang and Uye 1997) although it can also be found in the China Seas and in the nearby regions (Razouls et al. 2005-2013; Brodskii 1950; Shen and Lee 1963; Tanaka 1966). Its invasion history started in the 1960s in Hawaii, arriving there through ballast water (Jones, 1966). Over the years, it has colonized several areas in the American and Australian regions (Choi et al. 2005; Fleminger and Hendrix Kramer 1988; Greenwood 1976; Orsi and Walter 1991).

P. marinus is now commonly found in several Pacific and Indian bays (e.g., Fleminger and Hendrix Kramer 1988; Grindley and Grice 1969; Islam and Tanaka 2009; Jones 1966; Walter 1986), and recently, its presence has been recorded in the North Sea (Brylinski et al. 2012; Jha et al. 2013).

In October 2008, P. marinus was first recorded in Lake Faro (Zagami, personal observations) a small coastal lake along the North-Eastern Sicilian coast (southern Tyrrhenian Sea). Since its first introduction in this basin, the copepod has become the fourth most abundant copepod species. It occurrs (on average, $0.5 \%$ of the copepod assemblage), with a maximum of $3.9 \times$ $10^{3}$ individuals (ind.) per cubic metre representing an annual average of $0.5 \%$ of a copepod assemblage dominated by Acartidae and Oithonidae (Pansera 2011).

The lake has peculiar hydrological features, with a quasi-permanent anoxic layer in its deepest part. The depth of this layer varies during the year with a maximum summertime extension of the epilimnion of $15 \mathrm{~m}$ (Pansera 2011 and references therein). Owing to the presence of oxygen-depleted layer, in the central part of Lake Faro, P. marinus has changed its habit, becoming truly planktonic. Abundances are much higher in the water column in the centre of the lake than expected for a demersal copepod during light hours (Pansera 2011). Consequently, studying the swimming behaviour of adult stages is an important step towards the understanding of the biology of $P$. marinus in its new habitat.

This work is aimed at analysing the swimming behaviour of $P$. marinus in order to improve our knowledge of its biological and ecological traits. For the first time, using video recordings, the swimming behaviour of males, females and ovigerous females of $P$. marinus freely moving in a microcosm has been studied. $P$. marinus was filmed in the presence and absence of food to evaluate if the presence of prey might affect its swimming motion. The analysis of individual behaviour has been extensively used in the literature to investigate different aspects of copepod biology and ecology, such as searching for a mate and/or food or their responses under different conditions (e.g. Fields and Yen 1997; Henriksen et al. 2007; Hwang and Turner 1995; Jiang and Paffenhöfer 2008; Kazutaka and Tiselius 2005; Svensen and Kiørboe 2000; Uttieri et al. 2007, 2008). The strategies adopted by a copepod to encounter food, to avoid predators, to encounter and recognize mates and to move through the water column determine the probability of survival for each individual, with consequences affecting the whole population (Alcaraz et al. 2007). Swimming behaviour thus becomes fundamental for the comprehension of the ecology of a species (Visser 2011). However, only a few studies have focused on the motion of males, females and ovigerous females of the same species (e.g. Dur et al. 2010; Michalec et al. 2010, 2012). Our results show significant sex-dependent differences in the swimming behaviour of $P$. marinus, in contrast to the feeding modes that are similar between males and females (Uye and Kasahara 1983). In addition, our outcomes underline the different behavioural response to the presence of food, probably due to different dispersal and hiding strategies among males, females and ovigerous females.

\section{Methods}

\section{Cultures}

The copepods used for the experiments came from a population sampled in Lake Faro $\left(38^{\circ} 16^{\prime} \mathrm{N}, 15^{\circ} 38^{\prime} \mathrm{E}\right)$ through a gentle sampling performed with a WP2 net in May 2011. Animals were kept in plastic jars, with a variable rearing volume, thought to maintain an animal concentration not exceeding approximately 25 ind. per litre, in sterilized seawater at salinity of approximately 33 . Samples were kept at an environmental temperature, ranging between $15^{\circ} \mathrm{C}$ and $25^{\circ} \mathrm{C}$ throughout the rearing period and aeration of the volume was provided through gentle air bubbling. The animals where fed twice a week with Porphiridium cruentum at concentration of about $25 \times 10^{3}$ cells per litre. Typical total body lengths ranged between 1.2 and $1.6 \mathrm{~mm}$ for females and 0.8 and $1.2 \mathrm{~mm}$ for males.

\section{Video recordings}

The swimming behaviour of $P$. marinus was observed at the Laboratory of Oceanology and geosciences-Marine Station of Wimereux (France) between May and July 2011. Video recordings were performed using the same protocol described in Michalec et al. (2010). The 
copepods were sorted from the batch culture during the morning, and each individual was controlled under the microscope to verify its morphological integrity. All the observations were performed at the same time of the day to avoid any possible effect induced by different endogenous rhythms. Video recordings were carried out at a constant temperature of $19^{\circ} \mathrm{C}$ in a dark room to avoid any possible phototaxis. The copepods were acclimatised in the dark room at least $5 \mathrm{~min}$ before the recording began. The aquarium used for the observations $(10 \times 10 \times$ $10 \mathrm{~cm}, 1 \mathrm{l}$ volume) was big enough to avoid a substantial side wall effect, and was lit from the bottom using a near infrared (IR) LED array (emitting at $880 \mathrm{~nm}$ ). The copepods were then filmed for $25 \mathrm{~min}$. At the beginning of each filming session, a reference grid was recorded to estimate a pixel-to-millimetre conversion factor.

The video recordings were performed with a SONY digital IR sensitive video camera recorder (DCR-HC96E, Tokyo, Japan) operating at a frequency of 25 frames per second and equipped with a Carl Zeiss lens (Oberkochen, Germany). The camera covered the entire volume of the aquarium from the side, filming the motion in a $x z$ plane along the horizontal and vertical axes. The aquarium was covered with a Plexiglas lid to avoid any disturbance that could alter the motion of the animals.

Each set of experiments was performed for males, females and ovigerous females separately, both in the presence and absence of food to investigate the sex-specific motion features. In both sets of experiments, 25 copepods of the same sex and stage were gently placed in the aquarium. The number allowed the observation of several copepods moving in the aquarium, whilst overcoming the boundary-sticking tendency of $P$. marinus at the same time (as reported for Pseudodiaptomus annandalei by Michalec et al. 2010), and without inducing excessive stress due to overcrowding. In the second set of experiments, a quantity in excess $\left(50 \times 10^{3}\right.$ cells per litre) of $P$. cruentum was added to the water. Filming durations were deliberately short enough to disregard the sedimentation of food, while at the same time guaranteeing an effective recording of the motion behaviour.

Three replicates were performed for each experiment, for a total of 75 females, 75 males and 75 ovigerous females for each treatment. Animals were not fed for several hours before the beginning of the experiments. Animals used for video observations were not put into the culture again. Each time, new copepods were sorted with the aim of testing different individuals for each replicate and each experimental condition.

\section{Digitalization and extraction of the trajectories}

The trajectories were recorded on miniDV cassettes and then digitalized and imported into Adobe Premiere Pro 2.0 (Adobe Systems Incorporated, San Jose, CA, USA) video editing software. Each session was divided into 5min sequences to allow the analysing software (LabTrack version 2.1, BioRAS ApS, Copenhagen, Denmark) to extract the two-dimensional coordinates of the swimming tracks. Only the central area of the video image was taken into account to avoid the reflection of light from the sides of the aquarium and to avoid tracking animals moving on the walls. It should be noted that the software was only able to follow moving animals, thus losing the ones who were stationary for a time longer than a few seconds.

Before track analysis, data were filtered to remove spikes and noise: all trajectories shorter than 50 frames $(=2 \mathrm{~s})$ were discarded and when the distance between two successive steps was higher than 20 pixels along $x$ or $z$ axes, a single track was divided into two tracks and then inspected again. All resulting trajectories were singularly plotted and assessed visually, disregarding excessively noisy tracks. The tracks were analysed following the protocol of Dur et al. (2010) in order to allow a comparison between P. marinus and P. annandalei (Dur et al. 2010). In particular, the motion of the copepods was quantitatively analysed evaluating the speed and the swimming/rest time, and using symbolic analysis (Dur et al. 2010; Moison et al. 2009; Schmitt et al. 2006; Vandromme et al. 2010).

\section{Track analysis}

The instantaneous distance $d_{t}$ in millimetres at each time step was calculated as follows:

$$
d_{t}=\sqrt{\left(x_{t+1}-x_{t}\right)^{2}+\left(z_{t+1}-z_{t}\right)^{2}}
$$

where $\left(x_{t}, z_{t}\right)$ and $\left(x_{t+1}, z_{t+1}\right)$ were the positions of the copepod at time $t$ and $t+1$, respectively. The total displacement between the start and the end of the track was then calculated as the sum of the instantaneous displacements $d_{t} . d_{t}$ values were then multiplied by the camera frame rate $(f=25 \mathrm{~Hz})$ to retrieve instantaneous swimming speeds $V$ in millimetres per second. Speed components along $x$ $\left(V_{x}\right)$ and $\mathrm{z}\left(V_{z}\right)$ directions were also calculated.

A symbolic analysis was performed on the instantaneous velocities of each track to elucidate possible patterns in the swimming behaviour (Schmitt et al. 2006). Following the same approach used by other authors for copepod behavioural studies (e.g., Dur et al., 2011a; Michalec et al. 2010 and references therein), the activity of P. marinus was divided into four possible modalities on the basis of swimming speed magnitude and the direction of motion:

- Breaking, when resting without actively moving, or when hovering $\left(V \leq 1 \mathrm{~mm} \mathrm{~s}^{-1}\right)$;

- Cruising, when moving slowly in every direction with a moderate velocity $\left(1<V<20 \mathrm{~mm} \mathrm{~s}^{-1}\right)$; 
- Jumping, instantaneous high velocity movements in every direction $\left(V \geq 20 \mathrm{~mm} \mathrm{~s}^{-1}\right)$;

- Sinking, when there was no motion along the horizontal axis $\left(V_{x}=0\right)$ and the motion was directed downward at a maximum speed $V_{z}=3 \mathrm{~mm} \mathrm{~s}^{-1}$.

Although 2D video recording may have some problems in recognizing actual sinking from downward motion (Dur et al. 2011a), in P. marinus, no downward motion was observed in the registered tracks, and thus sinking was not scored in this study. The total time spent in each state was calculated in percentage in both sets of experiments (with and without food). Finally, the mean residence time in each state, i.e. the average amount of time that a copepod spent in a particular state consecutively, as well as a study on the transition probability, considering the chances of transition from one state to all the others were calculated. Both the residence time and the transition probability were represented as probability distribution functions as in Dur et al. (2010). The cases in which movement is completely random are defined by a first-order Markovian

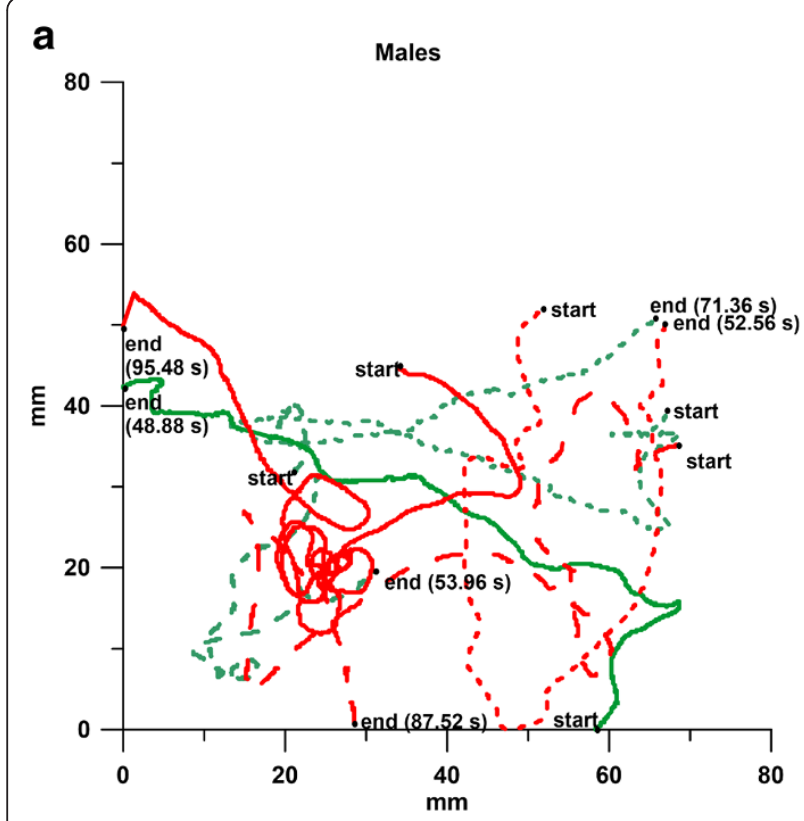

\section{b}

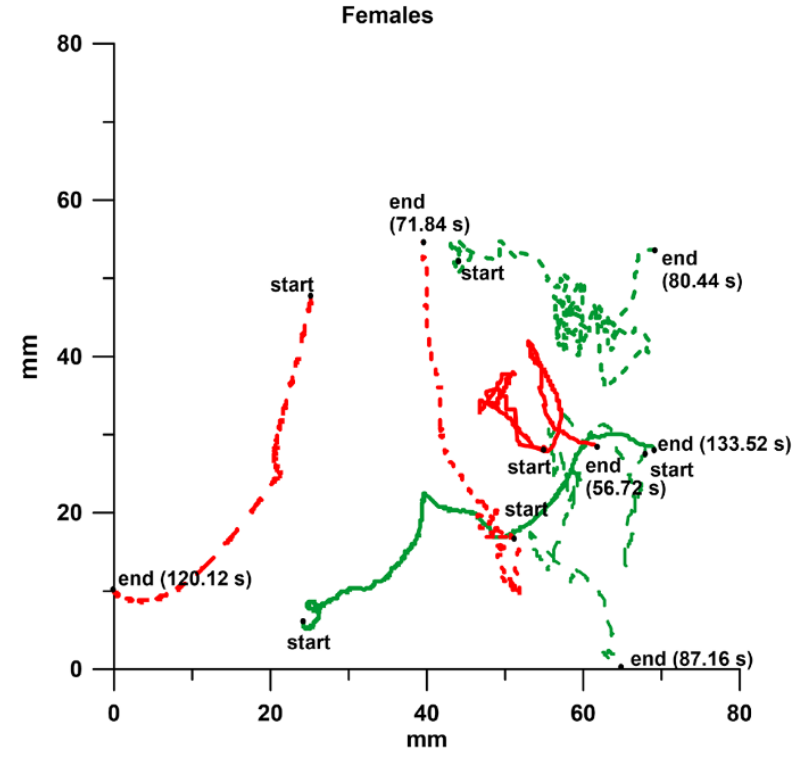

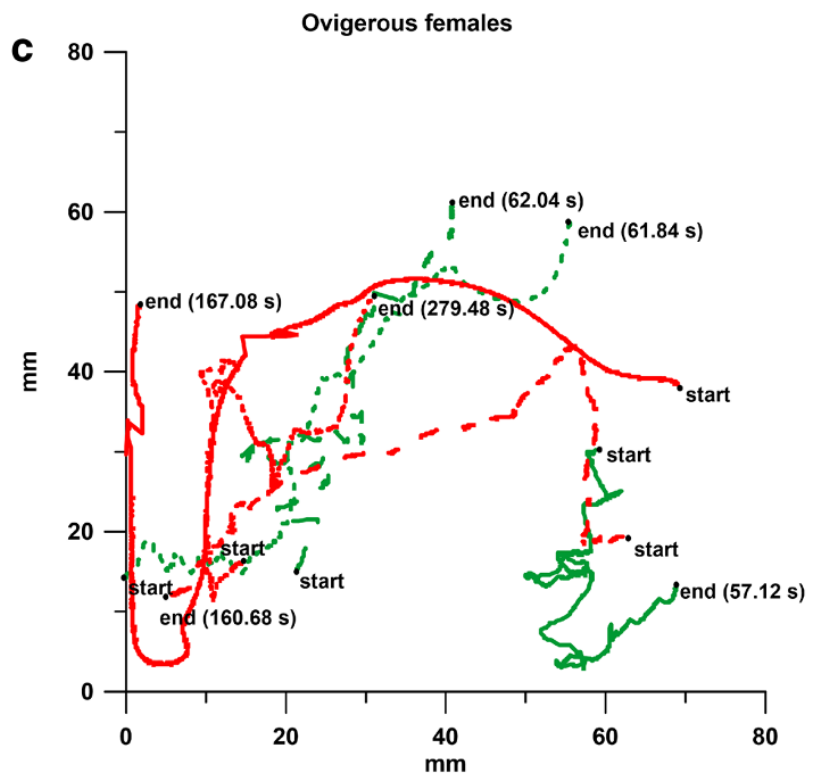

Figure 1 Examples of individual trajectories of (a) males, (b) non-ovigerous females and (c) ovigerous females of $P$. marinus. In conditions without food (red) and in presence of food in excess (green). 
process (i.e. for a Markov chain, see, e.g. Feller 1968, or the Appendix in Cencini et al. 1999). In a Markovian process, there is no memory of states earlier than the immediately previous one, and the probability $p_{i}(t)$ of staying for a time $t$ in the state $i$ (where $i$ in this case can be breaking, sinking, cruising or jumping) is given by

$$
p_{i}(t)=\left(P_{i i}\right)^{t}=e^{-t / T_{i}}
$$

where $T_{i}=-1 / \log P_{i i}$ is the characteristic time of the exponential decrease given by the earlier relation. This means that in a Markovian process, there should be an exponential fall off of the residence time (Dur et al. 2010; Gillespie 1992; Schmitt et al. 2006); however, if this condition is not satisfied, the process displays a longer memory and the movement cannot be described by a Markovian, memory-free process.

Mean swimming speeds were analysed through a Kolmogorov-Smirnov test to verify whether they were normally distributed or not. A preliminary analysis of the results obtained by the symbolic analysis revealed that approximately half of the time was spent in the breaking state. To avoid a bias in the calculation, mean swimming speeds were calculated as the average of the non-zero instantaneous values for each individual track. Maximum swimming speeds were calculated along the $x$ and along the $z$ axes, and the total mean speed was calculated for each track.

In addition, a non-parametric test (Mann and Whitney 1947) was used to compare the mean swimming speeds of each group in filtered water versus feeding conditions: a null $h$ value indicated that samples were statistically similar, whereas the significance of the test was reported with a $P$ value, with $P<0.05$ indicating statistically different values.

\section{Results}

Six groups of data will be considered in the following sections: males, females and ovigerous females swimming in filtered water; males, females and ovigerous females swimming in water enriched with a high concentration of food.

\section{General observations}

Preliminary laboratory observations revealed that most individuals of $P$. marinus were usually located near the bottom of the aquarium, creating feeding currents, making short movements in proximity to the bottom and swimming along the water column at night, similarly to other demersal species such as $P$. annandalei (Dur et al. 2010) or Oithona colcarva (Ohlhorst 1982).

The video recordings showed that males swam through long explorative trajectories all along the aquarium width both in the presence and in absence of food
(Figure 1a). Non-ovigerous females, instead, swam the least in both conditions, with relocation events interrupted by long pauses (Figure 1b). Ovigerous females' motion features were intermediate between non-ovigerous females and males when swimming in filtered water (Figure 1c). In this case, the behaviour was similar to that of non-ovigerous females, but moving more actively, sometimes spanning considerable distances like the males. When food was added to the medium, ovigerous females remained motionless for most of the time (Figure 1c) and for this reason, only a relatively small number of trajectories was extracted from the video recordings.

The total number of trajectories collected for each set of experiments (for males, females and ovigerous females without food and with food), together with the mean track durations and lengths in millimetres, are reported in Table 1.

\section{Swimming speeds}

Mean and maximum swimming speeds (total speed $V, V_{x}$ and $V_{z}$ components along with their maximum values $V_{x} \max$ and $V_{z} \max$ ) were calculated for each trajectory (Table 2). The mean swimming speeds were smallest for males (Table 2) $\left(V=6 \pm 3 \mathrm{~mm} \mathrm{~s}^{-1}\right.$ without food and $V=$ $7 \pm 3 \mathrm{~mm} \mathrm{~s}^{-1}$ with food), largest for females $(V=8 \pm$ $5 \mathrm{~mm} \mathrm{~s}^{-1}$ without food and $V=9 \pm 8 \mathrm{~mm} \mathrm{~s}^{-1}$ with food) and intermediate for ovigerous females $\left(V=8 \pm 5 \mathrm{~mm} \mathrm{~s}^{-1}\right.$ both with and without food). The maximum speed (not shown in Table 2), instead, was largest for males $\left(130 \mathrm{~mm} \mathrm{~s}^{-1}\right)$ and not influenced by the presence of food. As for females and ovigerous females, it ranged between $112 \mathrm{~mm} \mathrm{~s}^{-1}$ in the absence of food and $127 \mathrm{~mm} \mathrm{~s}^{-1}$ when food was present. The Mann-Whitney test applied to compare each experimental group without and with food confirmed that non-ovigerous and ovigerous females behave differently in the two conditions, while male speeds did not differ significantly in the two treatments (Table 3).

Table 1 Adult stages of $P$. marinus

\begin{tabular}{|c|c|c|c|}
\hline Case & $\begin{array}{l}\text { Number } \\
\text { of tracks } \\
\text { obtained }\end{array}$ & $\begin{array}{l}\text { Trajectory } \\
\text { duration }(\mathrm{s}) \\
\text { (mean } \pm \text { SD) } \\
\end{array}$ & $\begin{array}{l}\text { Trajectory } \\
\text { length }(\mathrm{mm}) \\
(\text { mean } \pm \text { SD) }\end{array}$ \\
\hline \multicolumn{4}{|l|}{ Filtered water } \\
\hline Males & 289 & $15 \pm 40$ & $90 \pm 40$ \\
\hline Females & 35 & $29 \pm 32$ & $100 \pm 50$ \\
\hline Ovigerous f. & 155 & $20 \pm 36$ & $110 \pm 50$ \\
\hline \multicolumn{4}{|l|}{ Food } \\
\hline Males & 268 & $20 \pm 17$ & $90 \pm 40$ \\
\hline Females & 42 & $24 \pm 31$ & $130 \pm 60$ \\
\hline Ovigerous f. & 57 & $12 \pm 17$ & $90 \pm 50$ \\
\hline
\end{tabular}

Number of tracks and track durations (s) and lengths $(\mathrm{mm})$ (mean values \pm standard deviation (SD)) for all adult stages of $P$. marinus in filtered water and with food 
Table 2 Mean speed values ( \pm standard deviation, SD) in millimetres per second

\begin{tabular}{|c|c|c|c|c|c|}
\hline Case & $\begin{array}{l}V_{x}\left(m_{e a n} \pm S D\right) \\
\left(\mathrm{mm} \mathrm{s}^{-1}\right)\end{array}$ & $\begin{array}{l}V_{z}\left(\mathrm{mean}^{-1} \pm \mathrm{SD}\right) \\
\left(\mathrm{mm} \mathrm{s}^{-1}\right)\end{array}$ & $\begin{array}{l}V\left(\mathrm{mean}^{-1} \pm \mathrm{SD}\right) \\
\left(\mathrm{mm} \mathrm{s}^{-1}\right)\end{array}$ & $\begin{array}{l}V_{x} \max (\text { mean } \pm S D) \\
\left(\mathrm{mm} \mathrm{s}^{-1}\right)\end{array}$ & $\begin{array}{l}\begin{array}{l}V_{z} \max (\text { mean } \pm S D) \\
\left(\mathrm{mm} \mathrm{s}^{-1}\right)\end{array} \\
\end{array}$ \\
\hline \multicolumn{6}{|l|}{ Filtered water } \\
\hline Males & $6 \pm 3$ & $6 \pm 3$ & $6 \pm 3$ & $16 \pm 18$ & $20 \pm 21$ \\
\hline Females & $7 \pm 6$ & $7 \pm 6$ & $8 \pm 5$ & $22 \pm 24$ & $31 \pm 30$ \\
\hline Ovigerous f. & $6 \pm 5$ & $6 \pm 5$ & $8 \pm 5$ & $21 \pm 23$ & $24 \pm 23$ \\
\hline \multicolumn{6}{|l|}{ Food } \\
\hline Males & $6 \pm 3$ & $6 \pm 5$ & $7 \pm 3$ & $20 \pm 62$ & $21 \pm 54$ \\
\hline Females & $8 \pm 7$ & $7 \pm 6$ & $9 \pm 8$ & $36 \pm 23$ & $45 \pm 25$ \\
\hline Ovigerous f. & $7 \pm 6$ & $6 \pm 4$ & $8 \pm 5$ & $27 \pm 26$ & $24 \pm 20$ \\
\hline
\end{tabular}

Mean speed values ( \pm standard deviation, SD) in millimetres per second for males, females and ovigerous females of $P$. marinus in filtered water and with food.

Swimming speeds were further analysed by looking at their probability distribution function, shown in Figure 2. The Kolmogorov-Smirnov test revealed that only nonovigerous females swimming speeds did not follow a normal distribution. Male swimming speed was the least influenced by the presence of food: the distributions in both cases were very similar and the mean values were close to each other. Non-ovigerous and ovigerous females were more influenced by the presence of food: the probability distributions were quite different, the function describing behaviour in food conditions following a different trend with respect to the case without food.

\section{Symbolic analysis}

The subdivision of motion in different states on the basis of the swimming speed revealed no sinking events in any of the recorded trajectories (Figure 3). The most common state was breaking (range of $49 \%$ to $67 \%$ ) in all tested conditions for males, females and ovigerous females, with the only exception of males in filtered water, followed by cruising ( $31 \%$ to $50 \%$ ) with generally rare jumping events (on average only $1 \%$ to $2 \%$ of the motion), usually with a transition to breaking. In filtered water, males showed the shortest time spent breaking while females showed higher values. In the presence of food, the time spent breaking by males was slightly influenced, while it diminished remarkably for non-ovigerous females, which increased the time spent cruising. For

Table 3 Mann-Whitney test results

\begin{tabular}{lll}
\hline & $\boldsymbol{P}$ value & $\boldsymbol{h}$ \\
\hline Males & $5.889 \times 10^{-6}$ & 1 \\
Females & $1.595 \times 10^{-1}$ & 0 \\
Ovigerous f. & $7.52 \times 10^{-2}$ & 0 \\
\hline
\end{tabular}

Mann-Whitney test comparing males, females and ovigerous females, in non-feeding versus feeding conditions. $P$ represents the $P$ value of the null hypothesis that data are samples from continuous distributions with equal medians, against the alternative that they are not. $h=1$ indicates a rejection of the null hypothesis, and $h=0$ indicates a failure to reject the null hypothesis at the $5 \%$ significance level. ovigerous females as well, although a small reduction in breaking was noticed (still remaining breaking the most common state), it should be underlined that the total number of tracks recorded in the case with food was heavily reduced, and overall ovigerous females tended to remain motionless for most of the time (Table 1).

Non-ovigerous females scored the highest jumping rate ( $5 \%$ in presence of food) of the entire set, with a general tendency to switch into cruising, except when in filtered water, where they switched more frequently into breaking.

The residence times (Table 4) showed that the probability distribution in food and no-food conditions was very similar in the case of males and attained different patterns when considering non-ovigerous and ovigerous females. In the latter cases, the residence times in the breaking state were consistently lower in presence of food, with respect to males (Figure 4). Although in nofood conditions, the standard deviation was always very high; when food was added, the standard deviation was consistently lower for both males and females, outlining a higher uniformity of time spent in this state.

No significant differences were noted between the food and no-food conditions for the mean residence times when cruising (Figure 5) and jumping. Residence time in the jumping state was always very low, as shown by symbolic analysis (data not shown).

\section{Discussion}

\section{Pseudodiaptomus marinus in Lake Faro}

This work outlined the different aspects of swimming behaviour in the copepod $P$. marinus, pointing out the differences existing between males and females as a response to their biological and ecological roles. Males tend to have a more marked explorative behaviour, associated with more active swimming and lower speed than females (Table 1 and Figure 3). Tracks are less convoluted and tended to explore the whole aquarium. Lower swimming speeds can be intended as a strategy to avoid 


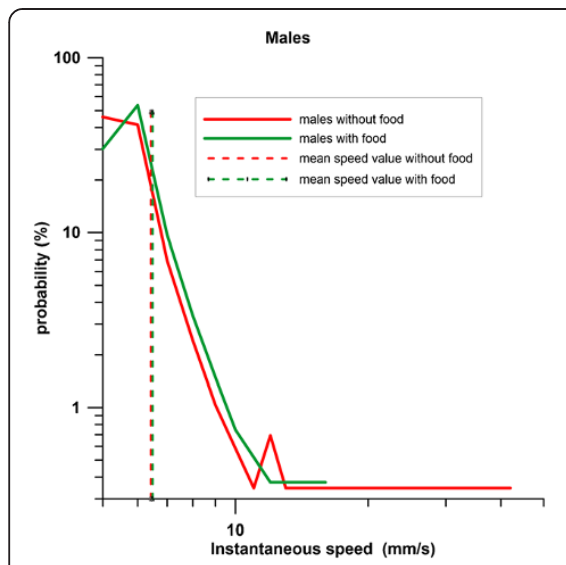

a
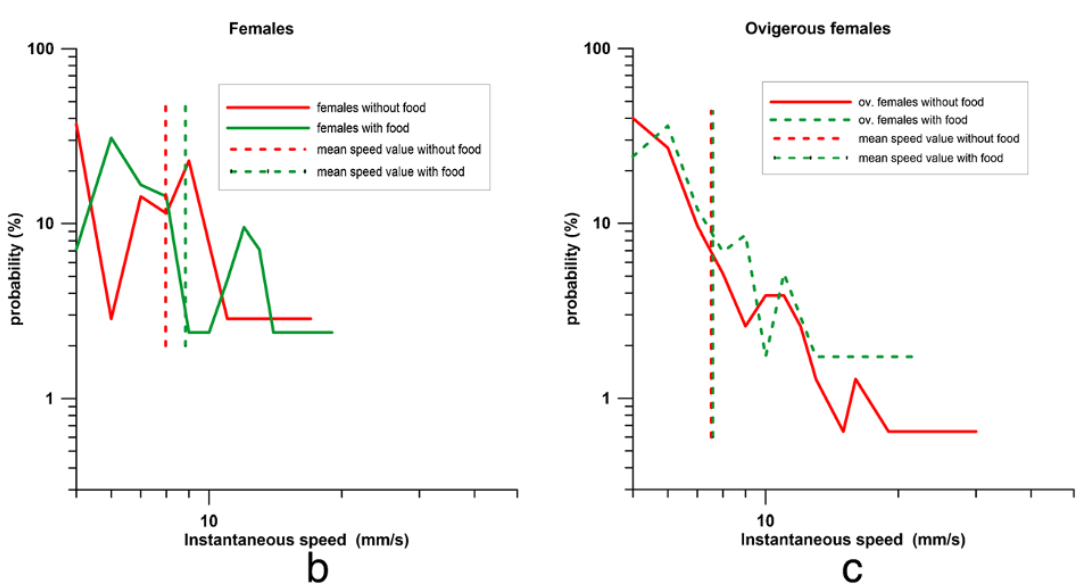

C

Figure 2 Probability density functions and mean speed values (dashed lines) of the mean swimming speed. (a) Males, (b) females and (c) ovigerous females of $P$. marinus in conditions without food (red line) and in presence of food in excess (green line). Mean speed values for males and ovigerous females in feeding and non-feeding conditions are overlapping.

being predated (Visser et al. 2009). Males and females respond differently to the presence of food. Male behaviour is almost unaffected by the presence of food, as shown by the similar values in the speeds and residence times in the two tested conditions. This behaviour is probably driven by different factors rather than food, such as those associated with the search for females. For females, instead, food was a much more important forcing factor shaping their behaviour, leading them to move for a longer time in search for food when it was not present, while reducing search time to a minimum when in presence of plentiful food to better exploit these resources. Ovigerous females, more than non-ovigerous ones, in conditions of abundance of food tend to hide on the bottom motionless and feeding. This tendency may be explained by the higher visibility to predators

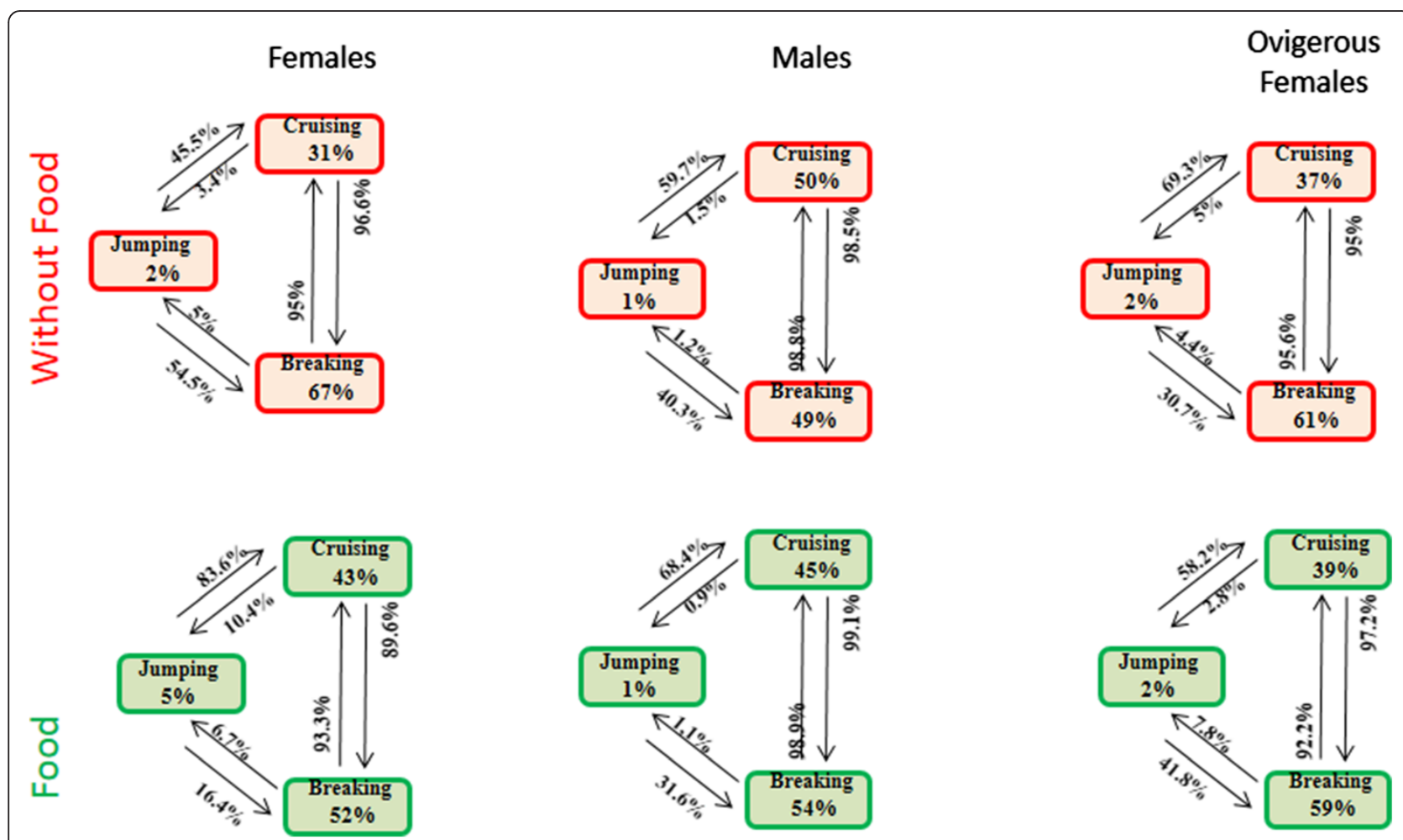

Figure 3 Symbolic analysis: representation of time spent in each state and of probability of transit from one state to another. 


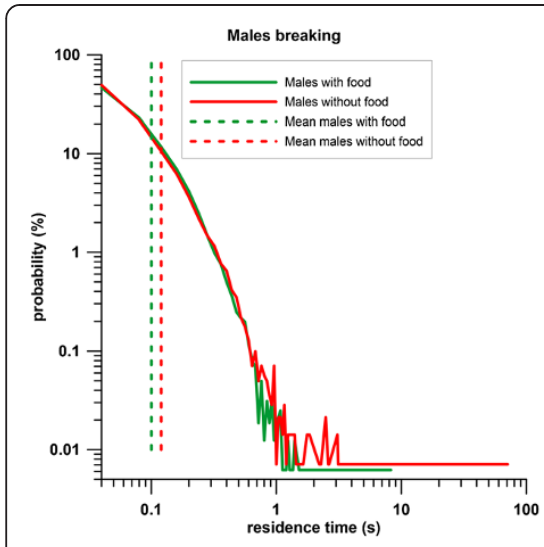

a

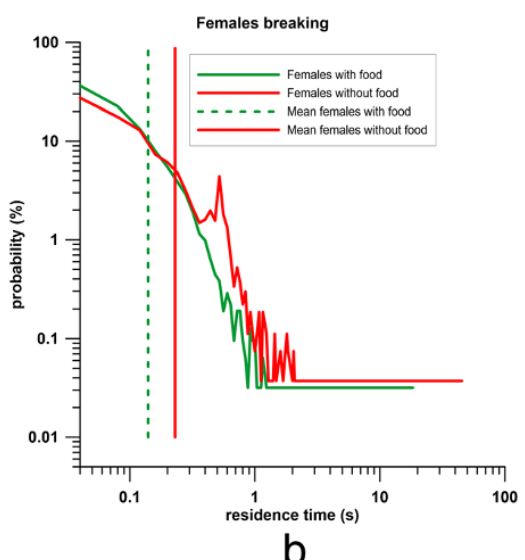

b

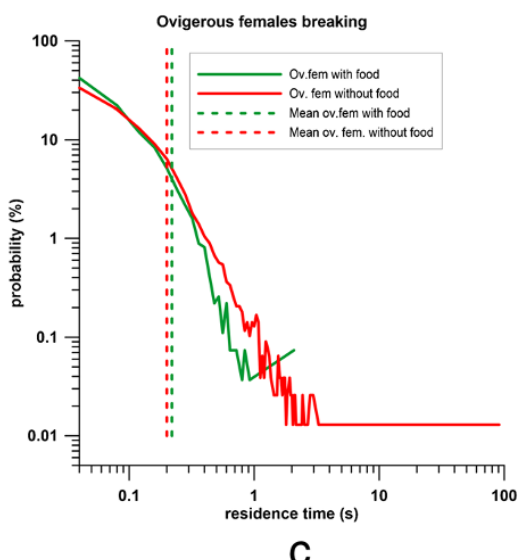

C

Figure 4 Probability distribution functions (solid lines) of residence time in breaking state and mean residence time values (dashed vertical lines). (a) Males, (b) females and (c) ovigerous females of P. marinus in conditions without food (red line) and in presence of food in excess (green line).

due to the presence of the egg sac and the marked colour. P. marinus generally has a pale colour, but ovigerous females are more reddish due to their high lipid content (32\%) (Fancett and Kimmerer 1985).

A common anti-predator strategy amongst copepods (and zooplankters in general) is the adoption of daily vertical migrations. These are generally induced by the presence of predators, often signalled by the occurrence of kairomone, which stimulate an avoidance reaction (Cohen and Forward 2009). As a common response, copepods generally move to the deeper layers or to the bottom during the day. For P. marinus, this tendency is still marked, with the animals being more abundant near the bottom along the coast where the bottom is not anoxic (Sabia 2012) and in the deepest layer ( 8 to $12 \mathrm{~m}$ ) above the anoxic barrier in the centre of the lake (Pansera 2011).

The general result of the present investigation shows a notable plasticity in the behaviour of $P$. marinus, which in the centre of the lake has switched to a fully planktonic behaviour to counteract for the anoxic deeper

Table 4 Residence times in different states

\begin{tabular}{llll}
\hline & $\begin{array}{l}\text { Breaking } \\
\text { (mean } \pm \text { SD) }\end{array}$ & $\begin{array}{l}\text { Cr) } \\
\text { (mean } \pm \text { SD) })(\mathbf{s})\end{array}$ & $\begin{array}{l}\text { Jumping } \\
\text { (mean } \pm \text { SD) (s) }\end{array}$ \\
\hline Filtered water & & & \\
Males & $0.12 \pm 0.79$ & $0.08 \pm 0.08$ & $0.05 \pm 0.02$ \\
Females & $0.23 \pm 0.91$ & $0.06 \pm 0.04$ & $0.04 \pm 0.02$ \\
Ovigerous f. & $0.20 \pm 1.36$ & $0.07 \pm 0.06$ & $0.06 \pm 0.05$ \\
Food & & & \\
Males & $0.10 \pm 0.12$ & $0.08 \pm 0.07$ & $0.04 \pm 0.02$ \\
Females & $0.14 \pm 0.39$ & $0.07 \pm 0.05$ & $0.05 \pm 0.03$ \\
Ovigerous f. & $0.11 \pm 0.11$ & $0.07 \pm 0.06$ & $0.03 \pm 0.02$ \\
\hline
\end{tabular}

Symbolic analysis: residence times in seconds of each reproductive stage in each possible state in case of filtered water and in case of food in excess. layers. The typical epibenthic behaviour of the species, however, is maintained by those individuals living along the shores of Lake Faro, where the bottom is oxygenated and the species showed highest abundances during the warm season with respect to all the other ones (Sabia et al. 2012).

The active motion behaviour of males and females is characterized by a high percentage of time spent cruising, which is considered optimal when foraging at low turbulence levels (Visser et al. 2009), a condition likely encountered in Lake Faro with its almost stable stratification (Leonardi et al. 2009 and references therein). In addition, the high abundance of food resources, together with a modest mixing rate and appropriate temperature (between $10^{\circ} \mathrm{C}$ and $28^{\circ} \mathrm{C}$ ) and salinity ranges in Lake Faro (between 34 and 37, Pansera 2011), have likely provided the newly introduced $P$. marinus a suitable environment for settling. At the same time, although other demersal species are present in Lake Faro, P. marinus is the only demersal copepod species displaying motion alternated with long pauses and detritivorous feeding (Zagami and Brugnano, 2013).

Taken together, these factors may allow an efficient niche separation from the other competing copepods present in the system and may represent a proficient ecological mechanism enhancing the capability of $P$. marinus of invading new areas.

\section{P. marinus and P. annandalei: a comparison of their behavioural patterns}

Several studies analysed copepod swimming behaviour with different video recording techniques: most of them focused only on female or male swimming behaviour (e.g. Lillelund and Lasker 1971; Paffenhöfer and Mazzocchi 2002), while only a few compared males, females and 

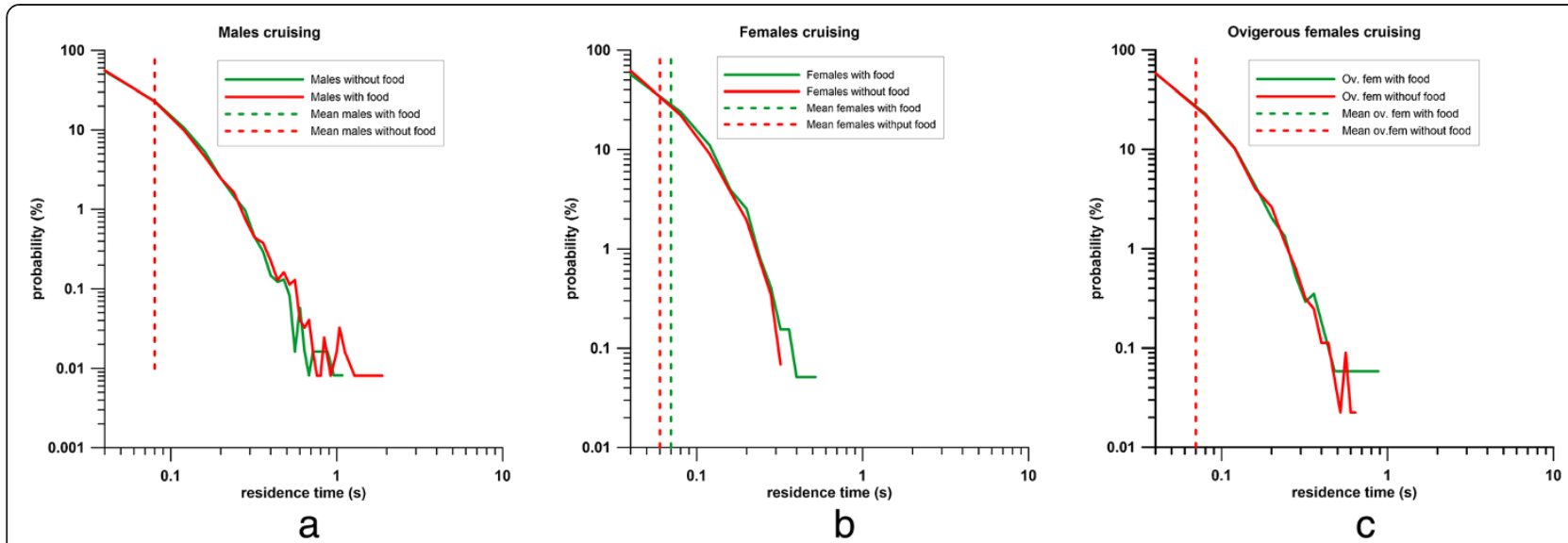

Figure 5 Probability distribution functions (solid lines) of residence time in cruising state and mean residence time values (dashed vertical lines). (a) Males, (b) females and (c) ovigerous females of P. marinus in conditions without food (red line) and in presence of food in excess (green line).

ovigerous females (Seuront 2006; Dur et al. 2010; Michalec et al. 2010, 2012, Michalec et al. 2013a, Michalec et al. 2013b). In particular, Dur et al. (2010) compared the different swimming behaviours of the three adult stages of Pseudodiaptomus annandalei, a congeneric species of $P$. marinus living in the China seas and in the Indian Ocean. As mentioned in a previous section, the present work applies the same analytical protocol as in Dur et al. (2010). However, in the present study, the swimming behaviour of $P$. marinus has also been investigated in the presence of food (unlike Dur et al. 2010), so as to appreciate if and how the occurrence of prey might alter the motion. The comparison between $P$. marinus and $P$. annandalei may allow us to derive conclusions on the differentiation of behaviour between two representatives of the same genus. Both species have similar sizes (Table 5) and are demersal, spending part of the time beneath the substrate as also reported for the congeneric species Pseudodiaptomus forbesi and Pseudodiaptomus inopinus (Cordell et al. 2007; Shang et al. 2008). In addition, both P. marinus and P. annandalei showed marked sex-specific behavioural features summarized in Table 5: male swimming patterns are slower than those of ovigerous and non-ovigerous females (differently from the more frequent evidence that males swim faster than the conspecific females; e.g. Kiørboe and Bagøien 2005). In both species, males swim more actively than females (as reported also for Pseudocalanus elongatus and Temora longicornis; Kiørboe 2008). It should be taken into account that in both species, males are smaller than females, and this may explain the lower swimming speeds of the males. For P. marinus sorted from Lake Faro, speeds rescale as 5.63 body length per second for females and 4.96 body length per second for males, but no total body length estimate is available for $P$. annandalei used by Dur et al. (2010).

Lower swimming speeds and longer time spent swimming in males may also indicate a possible common mating strategy for the two species. Mating experiments performed on P. annandalei (Dur et al. 2011b, 2012; Lee et al. 2011) showed that this species perceives stimuli from the mate mainly through chemical cues. Morphological analyses of the antennulae (A1) of male P. marinus revealed the presence of numerous aesthetascs. The presence of aesthetascs is common in copepod males and

Table 5 Comparative data of the swimming behaviour of the two congeneric species by Dur et al. 2010

\begin{tabular}{|c|c|c|c|c|c|c|}
\hline & Prosome length $(\mathrm{mm})$ & Mean speed $(\mathrm{mm} / \mathrm{s})$ & Breaking \% & Cruising \% & Jumping $\%$ & Sinking $\%$ \\
\hline \multicolumn{7}{|l|}{ P. marinus } \\
\hline Females & 0.93 & $8.0 \pm 5.2$ & 67 & 31 & 2 & - \\
\hline Males & 0.83 & $6.4 \pm 2.8$ & 49 & 50 & 1 & - \\
\hline Ovigerous f. & n.a. & $7.5 \pm 4.7$ & 61 & 37 & 2 & - \\
\hline \multicolumn{7}{|l|}{ P. annandalei } \\
\hline Females & 0.92 & $2.53 \pm 1.21$ & 54 & 34 & $<1$ & 12 \\
\hline Males & 0.74 & $2.77 \pm 1.27$ & 43 & 39 & $<1$ & 17 \\
\hline Ovigerous f. & n.a. & $2.87 \pm 1.09$ & 43 & 36 & 1 & 20 \\
\hline
\end{tabular}


suggests that the species relies on chemical cues to find a mate (Mauchline 1988). Both in P. marinus and in $P$. annandalei, breaking is the dominant state, with similar values for males but with more time spent breaking by females of P. marinus (Dur et al. 2010; present work). Both the species, and for all reproductive stages, the displacement does not follow a Brownian motion.

By contrast, $P$. marinus moves at a much higher mean speed and does not display sinking and looping, contrary to $P$. annandalei (Dur et al. 2010). P. annandalei thus seems to possess more pronounced 'swimming abilities', (Dur et al. 2010) than the simpler behaviour of P. marinus.

The differences in the behaviour of the two Pseudodiaptomus species may be induced by the differences in the environment in which they live and by the different habits of the two species. Though not being exclusively pelagic, $P$. annandalei thrives in areas characterized by fluctuating turbulent conditions (Lee et al. 2011 and references therein), where it has to move actively in the water column. P. marinus, instead, is usually considered a demersal species, living in highly eutrophic areas of internal sea, bays, harbours and brackish lakes (Razouls et al. 2005-2013), often characterized by moderate hydrodynamic conditions. Attaching to the substrate, a typical behaviour of the Pseudodiaptomus genus (Fancett and Kimmerer 1985) is less pronounced in P. marinus, likely owing to experience less turbulent conditions, in comparison to P. annandalei.

Although the two congeneric species originated from the same region (Walter 1986) and share several habitats, only $P$. marinus is becoming one of the invasive species conquering new areas today. The environmental features of Lake Faro seem optimal for the establishment and successful proliferation of $P$. marinus. Other copepods of the same genus are well known for their invasive ability, i.e. Pseudodiaptomus inopinus and P. forbesi (Cordell et al. 2008). These species live in a more restricted salinity range, between freshwater and brackish (Cordell et al. 2007; Razouls et al. 2005-2013), compared to $P$. marinus. Together with $P$. marinus and $P$. annandalei, they also share the tendency to live in proximity of the bottom. The tendency of $P$. annandalei to attach to the substrate in presence of strong currents (Beyrend-Dur et al. 2013; Shang et al. 2008) was described for P. inopinus as well (Cordell et al. 2007). At present, however, the knowledge of the behavioural traits of $P$. inopinus and $P$. forbesi is not sufficient to depict common features with $P$. marinus, which would allow them to successfully invade new areas.

\section{Conclusions}

The study of swimming behaviour of $P$. marinus explains how the peculiar hydrological and bathymetric features of Lake Faro allowed this species to successfully survive in such lake. To tackle this strong environmental constraint, the copepod has evolved a fully pelagic attitude in correspondence to the deoxygenated part of Lake Faro, avoiding the bottom and living in the water column all day (Sabia et al. 2012), though preserving its benthic behaviour along the shores. The presence of individual variations in the behaviour of individuals within a population is an important factor favouring the outcome of a new invasion (Wolf and Weissing 2012), and provides a basis to predict potential invasiveness (Carere and Gherardi 2013). The plasticity in the behaviour of $P$. marinus can be considered as a major factor, enhancing its capacity of colonising new environments.

The more specialized behaviour displayed by $P$. annandalei may be detrimental for the colonization of new habitats, although more details in the explanation of the non-invasivity of $P$. annandalei and the invasiveness of $P$. marinus, $P$. forbesi and P. inopinus should also be searched in their biological traits.

\section{Competing interests}

The authors declare that they have no competing interests.

\section{Authors' contributions}

LS, MU, FGS, GZ, EZ and SS conceived the study, interpreted the results and were involved in drafting the manuscript. LS, MU, FGS and SS designed the experiments. All authors read and approved the final manuscript.

\section{Acknowledgements}

This paper is a part of the PhD thesis of L. Sabia defended in March 2012. We thank all members of Animal Biology and Marine Ecology Laboratory in Messina, in particular Prof. L. Guglielmo, Dr. M. Pansera and Dr. C. Brugnano for useful information and their help during the course of L.S. PhD, and all members of S. S's team in Wimereux for their help during the experiments and in maintaining the copepod cultures. This work was supported by a doctoral fellowship of the University of Messina [to L. S.], by the PRES 'Université Lille Nord de France' [to L. S.], by the MOKA project (Modelling and Observation of zooplanKtonic orgAnisms) financed by the Italian Ministry of Education, University and Research [ID: RBFR10VF6M to M. U.]. This paper is a contribution to the COPEFISH project (coordinated by S. S.) and funded by the Conseil Régional Nord Pas de Calais. The authors are grateful to Prof. G. Boxshall, Dr. A. Visser, Dr. M. G. Mazzocchi and an anonymous Reviewer for useful comments and suggestions. M. U. acknowledges M. Pottek for the design of the MOKA cartoon. L.S. is grateful to Dr. S. Batenburg for useful suggestion and a final check of this paper.

\section{Author details}

${ }^{1}$ Department of Biological and Environmental Sciences, University of Messina, V.le F. Stagno d'Alcontres,31, S. Agata-Messina 98166, Italy. ${ }^{2}$ Department of Science and Technologies, University of Naples 'Parthenope', Centro Direzionale di Napoli, Isola C4, Napoli 80143, Italy. 'Laboratoire d'Océanologie et de Géosciences UMR CNRS 8187 LOG, Université Lille 1, Station Marine 28 avenue Foch, Wimereux 62930, France. ${ }^{4}$ Present address: Department of Sciences and Technologies, University of Naples 'Parthenope', Centro Direzionale di Napoli - Isola C4, Napoli 80143, Italy.

Received: 18 December 2013 Accepted: 22 July 2014 Published: 15 August 2014

\section{References}

Alcaraz M, Saiz E, Calbet A (2007) Centropages behaviour: swimming and vertical migration. Prog Oceanogr 72:121-136

Beyrend-Dur D, Souissi S, Hwang J-S (2013) Population dynamics of calanoid copepods in the subtropical mesohaline Danshuei Estuary (Taiwan) and typhoon effects. Ecol Res 28(5):771-780 
Brodskii KA (1950) Calanoida of the Far Eastern Seas and Polar Basin of the U.S.S.R Opredeliteli Po Faune SSSR. 35:1-442

Brylinski JM, Antajan E, Raud T, Vincent D (2012) First record of the Asian copepod Pseudodiaptomus marinus Sato, 1913 (Copepoda: Calanoida: Pseudodiaptomidae) in the southern bight of the North Sea along the coast of France. Aquat Invasions 7(4):577-584

Carere C, Gherardi F (2013) Animal personalities matter for biological invasions. TREE 28(1):6

Cencini M, Lacorata G, Vulpiani A, Zambianchi E (1999) Mixing in a meandering jet: a Markovian approximation. J Phys Oceanogr 29:2578-2594

Choi KH, Kimmerer W, Smith G, Ruiz GM, Lion K (2005) Post-exchange zooplankton in ballast water of ships entering the San Francisco estuary. J Plankton Res 27(7):707-714

Cohen JH, Forward RB (2009) Zooplankton diel vertical migration: a review of proximate control. Oceanogr Mar Biol Ann Rev 47:77-110

Cordell JR, Rasmussen M, Bollens SM (2007) Biology of the introduced copepod Pseudodiapotmus inpinus in a northeast Pacific estuary. Mar Ecol Prog Ser 333:213-227

Cordell JR, Bollens SM, Draheim R, Sytsma M (2008) Asian copepods on the move: recent invasions in the Columbia-Snake River system. ICES J Mar Sci 65:753-758

De Olazabal A, Tirelli V (2011) First record of the egg-carrying calanoid copepod Pseudodiaptomus marinus in the Adriatic Sea. Mar Biodivers Rec 4:1-4, doi:10.1017/S1755267211000935

Delpy F, Pagano M, Blanchot J, Carlotti F, Thibault-Botha D (2012) Man-induced hydrological changes, metazooplankton communities and invasive species in the Berre Lagoon (Mediterranean Sea, France). Mar Poll Bull 64:1921-1932

Dur G, Souissi S, Cheng S-H, Hwang J-S (2010) The different aspects in motion of the three reproductive stages of Pseudodiaptomus annandalei (Copepoda, Calanoida). J Plankton Res 32(4):423-440

Dur G, Souissi S, Schmitt FG, Beyrend-Dur D, Hwang J-S (2011a) Mating and mate choice in Pseudodiaptomus annandalei (Copepoda: Calanoida). J Exp Mar Biol Ecol 402:1-11

Dur G, Souissi S, Schmitt FG, Michalec FG, Mahjoub MS, Hwang J-S (2011b) Effect of animal density, volume and the use of 2D/3D recording on behavioral studies of copepods. Hydrobiologia 666:197-214, doi:10.1007/s10750-0100586-Z

Dur G, Souissi S, Schmitt FG, Cheng S-H, Hwang J-S (2012) Sex ratio and mating behavior in the calanoid copepod Pseudodiaptomus annandalei. Zool Stud 51(5):589-597

Fancett MS, Kimmerer W (1985) Vertical migration of the demersal copepod Pseudodiaptomus as a means of predator avoidance. J Exp Mar Biol Ecol 88(1):31-43

Feller W (1968) An introduction to probability theory and its applications, vol 1, 3rd edn. Wiley, Hoboken

Fields DM, Yen J (1997) The escape behavior of marine copepods in response to a quantifiable fluid mechanical disturbance. J Plankton Res 19(9):1289-1304

Fleminger A, Hendrix Kramer S (1988) Recent introduction of an Asian estuarine copepod, Pseudodiaptomus marinus (Copepoda: Calanoida), into southern California embayments. Mar Biol 98:535-541

Galil BS (2009) Taking stock: inventory of alien species in the Mediterranean Sea. Biol Invasions 11:359-372

Gillespie DT (1992) Markov processes. Academic Press, San Diego

Greenwood JG (1976) Calanoid copepods of Moreton Bay (Queensland) II. Families Calocalanidae to Centropagidae. Proc Soc Qld 88:49-67

Grindley JR, Grice JD (1969) A redescription of Pseudodiaptomus marinus Sato (Copepoda, Calanoida) and its occurrence at the Island of Mauritius. Crustaceana 16(2):125-134

Henriksen Cl, Saiz E, Calbet A, Hansen B (2007) Feeding activity and swimming patterns of Acartia grani and Oithona davisae nauplii in the presence of motile and non motile prey. Mar Ecol Prog Ser 331:119-129

Hirota R (1962) Species composition and seasonal changes of copepod fauna in the vicinity of Mukaishima. J Oceanogr Soc Japan 18:35-40

Hwang J-S, Turner JS (1995) Behaviour of Cyclopoid, Harparticoid and Calanoid copepods from coastal waters of Taiwan. PSZNI Mar Ecol 16(3):207-216

Islam MS, Tanaka M (2009) Diet and prey selection in larval and juvenile Japanese anchovy Engraulis japonicus in Ariake Bay, Japan. Aquat Ecol 43:549-558, doi:10.1007/s10452-008-9207-6

Jha U, Jetter A, Lindley JA, Postel L, Wootton M (2013) Extension of distribution of Pseudodiaptomus marinus, an introduced copepod, in the North Sea. Mar Biodivers Rec 6(e53):1-3, doi:10.1017/\$1755267213000286
Jiang H, Paffenhöfer G-A (2008) Hydrodinamic signal perception by the copepod Oithona plumifera. Mar Ecol Prog Ser 373:37-52

Jones EC (1966) A new record of Pseudodiaptomus marinus Sato (Copepoda, Calanoida) from brackish waters of Hawaii. Crustaceana 10(3):316-317

Kazutaka T, Tiselius P (2005) Ontogenic change of foraging behaviour during copepodite development of Acartia clausi. Mar Ecol Prog Ser 303:213-223

Kiørboe T (2008) Optimal swimming strategies in mate searching pelagic copepods. Oecologia 155:179-192

Kiørboe T, Bagøien E (2005) Motility patterns and mate encounters rates in planktonic copepods. Limnol Oceanogr 50(6):1999-2007

Lee C-H, Dahms H-U, Cheng S-H, Souissi S, Schmitt FG, Kumar R, Hwang J-S (2011) Mating behaviour of Pseudodiaptomus annandalei (Copepoda, Calanoida) at calm and hydrodynamically disturbed waters. Mar Biol 158(5):1085-1094, doi:10.1007/s00227-011-1632-8

Leonardi M, Azzaro F, Azzaro M, Caruso G, Mancuso M, Monticelli MS, Maimone G, La Ferla R, Raffa F, Zaccone R (2009) A multidisciplinary study of the Cape Peloro brackish area (Messina, Italy): characterisation of trophic conditions, microbial abundances and activities. Mar Ecol 30(1 SUPPL):33-42, doi:10.1111/j.1439-0485.2009.00320.x

Liang D, Uye S (1997) Population dynamics and production of the planktonic copepods in a eutrophic inlet of the Inland Sea of Japan. IV Pseudodiaptomus marinus the egg-carrying calanoid. Mar Biol 128:415-421

Lillelund K, Lasker R (1971) Laboratory studies of predation by marine copepods on fish larvae. Fish Bull 69(3):655-667

Mann HB, Whitney DR (1947) On a test of whether one of two random variables is stochastically larger than the other. Ann Math Stat 18(1):50-60, doi:10.1214/aoms/117773049

Mauchline J (1988) The biology of calanoid copepods, vol 33. Advances in Marine Biology, Academic Press, San Diego

Michalec FG, Souissi S, Dur G, Mahjoub MS, Schmitt FG, Hwang J-S (2010) Differences in behavioral responses of Eurytemora affinis (Copepoda, Calanoida) reproductive stages to salinity variations. J Plankton Res 32(6):805-813

Michalec FG, Holzner M, Hwang J-S, Souissi S (2012) Three dimensional observation of salinity-induced changes in the swimming behavior of the estuarine calanoid copepod Pseudodiaptomus annandalei. J Exp Mar Biol Ecol 438:24-31

Michalec FG, Holzner M, Menu D, Hwang J-S, Souissi S (2013a) Behavioral responses of the estuarine calanoid copepod Eurytemora affinis to sub-lethal concentrations of waterborne pollutants. Aquat Toxicol 138-139:129-138

Michalec FG, Ka S, Holzner M, Souissi S, lanora A, Hwang J-S (2013b) Changes in the swimming behavior of Pseudodiaptomus annandalei (Copepoda, Calanoida) adults exposed to the diatom toxin 2-trans, 4-trans decadiena. Harmful Algae 30:56-64

Moison M, Schmitt FG, Souissi S, Seuront L, Hwang J-S (2009) Symbolic dynamics and entropies of copepod behaviour under non turbulent and turbulent conditions. J Mar Syst 77:388-396

Ohlhorst SL (1982) Diel migration patterns of demersal reef zooplankton. J Exp Mar Biol Ecol 601:1-15

Orsi JJ, Walter CT (1991) Pseudodiaptomus forbesi and P. marinus (Copepoda: Calanoida) the latest copepod immigrants to California's Sacramento - San Joaquin estuary. Bull Plankton Soc Japan Special 553-556

Paffenhöfer G-A, Mazzocchi MG (2002) On some aspects of the behaviour of Oithona plumifera (Copepoda: Cyclopoida). J Plankton Res 24(2):129-135

Pansera M (2011) Uno studio dello zooplankton nel Lago di Faro, Messina, PhD Thesis. University of Messina, Messina

Razouls C, de Bovée F, Kouwenberg J, Desreumaux N (2005-2013) Diversity and geographic distribution of marine planktonic copepods. http://copepodes. obs-banyuls.fr/en/fichesp.php?sp=2320 Accessed 08/12/2013

Sabia L (2012) An integrated approach to the study of the swimming behaviour of Pseudodiaptomus marinus, PhD Thesis. University of Messina, Messina

Sabia L, Uttieri M, Pansera M, Souissi S, Schmitt FG, Zagami G, Zambianchi E (2012) First observations on the swimming behaviour of Pseudodiaptomus marinus from Lake Faro. Biologia Marina Mediterranea 19(1):240-241

Sato F (1913) Pelagic copepods (no. 1). In: Scientific Reports of the Hokkaido Fisheries Experimental Station 1., pp 1-79

Schmitt FG, Seuront L, Souissi S, Hwang J-S (2006) Scaling of swimming sequences in copepod behavior: data analysis and simulations. Physica A 364:287-296

Seuront $L$ (2006) Effect of salinity on the swimming behaviour of the estuarine calanoid copepod Eurytemora affinis. J Plankton Res 28(9):805-813

Shang X, Wang G, Li S (2008) Resisting flow - laboratory study of rheotaxis of the estuarine copepod Pseudodiaptomus annandalei. Mar Fresh Behav Physiol 41(2):109-124 
Shen CJ, Lee FS (1963) The estuarine Copepoda of Chiekong and Zaikong Rivers, Kwantung Province, China. Acta Zoologica Sinica 15(4):571-596

Svensen C, Kiørboe T (2000) Remote prey detection in Oithona similis: hydromechanical versus chemical cues. J Plankton Res 22(6):1155-1166

Tanaka O (1966) Neritic copepoda Calanoida from the North-West Coast of Kyusu. Proc Symp Crustaceans Ernakulam India 1:38-50

Uttieri M, Nihongi A, Mazzocchi MG, Strickler JR, Zambianchi E (2007) Pre-copulatory swimming behaviour of Leptodiaptomus ashlandi (Copepoda: Calanoida): a fractal approach. J Plankton Res 29(supplement 1):117-126

Uttieri M, Paffenhöfer G-A, Mazzocchi MG (2008) Prey capture in Clausocalanus. furcatus (Copepoda: Calanoida). The role of swimming behaviour. Mar Biol 153:925-935

Uye S, Kasahara S (1983) Grazing of various developmental stages of Pseudodipatomus marinus (Copepoda: Calanoida) on natural occurring particles. Bull Plankton Soc Japan 30(2):147-158

Uye S, Iway Y, Kasahara S (1982) Reproductive biology of Pseudodiaptomus marinus (Copepoda: Calanoida) in the Inland Sea of Japan. Bull Plankton Soc Japan 29(1):25-35

Valbonesi A, Harada E (1980) The veritcal distributions of some copepods and a mysid in a near-shore water of Tanabe Bay. Publ Seto Mar Bio Lab XXV(5/6):445-460

Vandromme P, Schmitt FG, Souissi S, Buskey EJ, Strickler JR, Wu CH, Hwang J-S (2010) Symbolic analysis of plankton swimming trajectories: case study of Strobilidium sp. (Protista) helical walking under various food conditions. Zool Stud 49(3):289-303

Visser AW (2011) Small, Wet and Rational. Dr. Techn. Dissertation. Technical University of Denmark, Copenhagen

Visser AW, Mariani P. Pigolotti S (2009) Swimming in turbulence: zooplankton fitness in terms of foraging effciency and predation risk. J Plankton Res 31(2):121-133

Walter CT (1986) New and poorly known Indo-Pacific species of Pseudodiaptomus (Copepoda: Calanoida), with a key to the species groups. J Plankton Res 8(1):129-168

Wolf M, Weissing FJ (2012) Animal personalities: consequences for ecology and evolution. TREE 27:452-461

Zagami G, Brugnano C (2013) Diel, seasonal and man-induced changes in copepod assemblages and diversity, with special emphasis on hyperbenthic calanoid species, in a Mediterranean meromictic system (Lake Faro). Mar Freshw Res 64:951-964

Zenetos A, Gofas S, Verlaque M, Cinar ME, Garcia Raso JE, Bianchi CN, Morri C, Azzurro E, Bilecenoglu M, Froglia C, Siokou I, Violanti D, Sfriso A, San Martin G, Giangrande A, Katan T, Ballesteros E, Ramos-Espla A, Mastrototaro F, Oca O, Zingone A, Gambi MC, Streftaris N (2010) Alien species in the Mediterranean Sea by 2010. A contribution to the application of European Union's Marine Strategy Framework Directive (MSFD). Part I. Spatial distribution. Mediterr Mar Sci 11(2):381-493

Zenetos A, Gofas S, Morri C, Rosso A, Violanti D, García Raso JE, García Raso JE, Cinar ME, Almogi-Labin A, Ates AS, Azzurro E, Ballesteros E, Bianchi CN, Bilecenoglu M, Gambi MC, Giangrande A, Gravili CH-KO, Karachle PK, Katsanevakis S, Lipej L, Mastrototaro F, Mineur F, Pancucci-Papadopoulou MA, Ramos Esplá A, Salas C, San Martín G, Sfriso A, Streftaris N, Verlaque M (2012) Alien species in the Mediterranean Sea by 2012. A contribution to the application of European Union's Marine Strategy Framework Directive (MSFD). Part 2. Introduction trends and pathways. Mediterr Mar Sci 13(2):328-352

doi:10.1186/s40555-014-0049-8

Cite this article as: Sabia et al:: Pseudodiaptomus marinus Sato, 1913, a new invasive copepod in Lake Faro (Sicily): observations on the swimming behaviour and the sex-dependent responses to food. Zoological Studies 2014 53:49.

\section{Submit your manuscript to a SpringerOpen ${ }^{\circ}$ journal and benefit from:}

- Convenient online submission

- Rigorous peer review

- Immediate publication on acceptance

- Open access: articles freely available online

- High visibility within the field

- Retaining the copyright to your article

Submit your next manuscript at $\gg$ springeropen.com 